\title{
APRENDIZAGEM PARTICIPATIVA DE MÃES E FAMILIARES SOBRE A SAÚDE DO RECÉM-NASCIDO: RELATO DE EXPERIÊNCIA
}

PARTICIPATIVE LEARNING OF MOTHERS AND FAMILY ABOUT

NEWBORN HEALTH: EXPERIENCE REPORT

*Luciana Mara Monti Fonseca, **Natália Del’Angelo, ***Fernanda Salim Ferreira de Castro, ****Carmen Gracinda Silvan Scochi

\section{RESUMO}

A educação em saúde é aspecto fundamental no processo saúde-doença, contribuindo na prevenção e reabilitação. O papel de educador na saúde geralmente cabe ao profissional de Enfermagem. Essa prática tem se dado, não raro, de forma tradicional, pela simples transmissão de conteúdos. Uma nova vertente da educação em saúde busca a autonomia dos sujeitos, utilizando metodologias ativas de aprendizagem e práticas participativas. Este trabalho relata a vivência de grupo formado com o intuito de potencializar a emancipação das famílias nos cuidados aos recém-nascidos, prematuros ou não, e construir o conhecimento através de colaboração e participação. As atividades educativas em grupo foram realizadas em dois hospitais de Ribeirão Preto, conduzidos por alunos de graduação e pós-graduação em Enfermagem sob orientação do pesquisador. As estratégias utilizadas nos grupos foram: jogos de tabuleiro e de cartas, cartilha e distribuição de figuras para discussão. Conclui-se, após participação dos envolvidos, que as atividades de educação em saúde contribuíram com o processo de construção e integração do saber de familiares e equipe de saúde neonatal e para a construção de uma assistência mais integral e humanizada, auxiliando na busca da emancipação das famílias dos bebês.

Palavras-chave: Enfermagem neonatal. Educação em saúde. Família.

\footnotetext{
* Professora doutora do Departamento de Enfermagem Materno-Infantil e Saúde Pública da Escola de Enfermagem de Ribeirão Preto da Universidade de São Paulo (EERP-USP) - R. Doutor Hortêncio Mendonça Ribeiro, I.265. - I4026-09o - Jd. Califórnia - Ribeirão Preto - SP - e-mail: lumonti@eerp.usp.br. ** Enfermeira e mestranda do Departamento de Enfermagem MaternoInfantil e Saúde Pública da EERP-USP. *** Enfermeira e mestranda do Departamento de Enfermagem Materno-Infantil e Saúde Pública da EERP-USP. ***** Professora titular do Departamento de Enfermagem Materno-Infantil e Saúde Pública da EERP-USP -e-mail: cscochi@eerp.usp.br.
} 


\section{ABSTRACT}

The health education is a crucial issue in health-disease process, contributing in prevention and rehab. The educator role in health usually behooves to nursing professional. This practice has been occurred in a traditional way, simply through content transmission. There is a new health education side that aims people' autonomy and participative practices. This study report the experiences of a group formed to potentiate family's emancipation in newborn care, preterm or not, and to build knowledge through collaboration and participation. Educative activities were realized in two hospitals of Ribeirão Preto, conducted by undergraduate and graduate students in nursing under supervisor orientation. The strategies used on groups were: board games, card game, educational guideline and distribution of pictures to discussion. After participation of involved people, it can be concluded that the educational activities contributed with build and integration process of know-how by families and neonatal health team, and for a more integral and humanized assistance helping to emancipate babies' families.

Key words: Neonatal nursing. Health education. Family. 


\section{INTRODUÇÃO}

A educação em saúde constitui aspecto fundamental no processo saúde-doença, atuando, sobretudo, na prevenção e reabilitação. Ela tem sido alvo de reflexão e busca de aperfeiçoamento no que tange à construção do conhecimento; acredita-se na mudança de ótica pela qual se analisa tal educação, avançando da simples transmissão de informações para a troca de experiências e saberes. Assim, confere melhores práticas educacionais aos profissionais de saúde que lidam diariamente com clientes destes serviços.

Toledo, Rodrigues e Chiesa [II] verificaram, em um trabalho de revisão de literatura, que a educação em saúde geralmente é atribuída ao profissional de enfermagem e tem sido realizada por simples transmissão de conteúdos. Tal forma de educação, denominada tradicional e criticada por Freire [6] pelo caráter unilateral de depósito de conhecimentos no aprendiz sem oportunidade de troca e compartilhamento de experiências, persiste na estrutura de muitas equipes de saúde, devido a uma formação majoritariamente biologicista e construída na hierarquia do saber.

Em contraposição aos estudos que descrevem a educação realizada de forma tradicional, Pereira [Io] afirma que educação em saúde consiste em mais que transmissão de informações; constitui-se de uma combinação de oportunidades que favorecem para a manutenção e promoção da saúde, ao utilizar práticas educativas que buscam a autonomia dos sujeitos na condução de sua própria vida. Essa afirmação corrobora com a elaboração de metodologias ativas de aprendizagem que, por dispor de recursos dinâmicos e valorizar a colaboração entre indivíduos, promove a educação em saúde de forma participativa, a partir do pressuposto que o profissional de saúde aprende também com o usuário do serviço enquanto compartilha com ele seus conhecimentos acerca dos temas abordados.

Machado et alli [8] ressaltam a importância de se estabelecer estratégias de aprendizagem que favoreçam o diálogo, a troca e a transdisciplinaridade entre saberes formais e informais, envolvendo diversos profissionais e o cliente. Em concordância com os autores, destacamos que, desta forma, é estabelecido um alicerce eficaz na busca da concretização da integralidade em saúde.

Portanto, é de fundamental importância a percepção das metodologias ativas de aprendizagem pelos profissionais de saúde, considerando que estes são membros ativos na orientação e educação em saúde de seus pacientes e que necessitam de aprimoramento nesta relação educativa, com o intuito de torná-la mais significativa, dinâmica e eficaz.

Um estudo realizado em 2005 com grupos de pacientes em educação em saúde alimentar aponta a deficiência de adesão dos pacientes em muitas orientações oferecidas no dia a dia, dada a superficialidade da comunicação entre profissionais da saúde e usuários do serviço de saúde, geralmente identificada na assistência, segundo Mafficiolli [9].

A realização de atividades em grupo permite maior interação entre os membros participantes, confrontando e aproximando suas realidades e permitindo a troca de experiências. Mafficiolli [9] ainda afirma que este recurso favoreceu os profissionais participantes em seu estudo, permitindo ampliar o olhar no que tange ao cotidiano dos pacientes. Isto se faz fundamental para a qualidade da assistência e da educação em saúde, uma vez que motiva o profissional a refletir sobre as mais diversas situações que influenciam e permeiam a execução de tarefas requeridas na prevenção em saúde.

É conhecido que a educação em saúde tem potencial para promover autonomia da família do recém-nascido, visando à alta hospitalar. A atuação dos profissionais junto ao preparo dos pais e familiares do bebê para que estes assumam os cuidados de seu filho recém-nascido no contexto familiar é crucial, uma vez que, através da educação em saúde, é conferido aos pais empoderamento do saber cuidar de seu bebê.

Espera-se que estas atividades de educação em saúde auxiliem na autonomia e emancipação de familiares para o cuidado hospitalar e domiciliar dos bebês, vislumbrando o cuidado centrado na família, integral e humanizado a esta clientela.

\section{OBJETIVO}

- Descrever o desenvolvimento de atividades educativas junto às famílias sobre os cuidados ao recémnascidos a termo e pré-termo. 


\section{AS ATIVIDADES DE EDUCAÇÃO EM SAÚDE JUNTO À CLIENTELA}

As atividades de educação em saúde foram realizadas por quatro estudantes de graduação em Enfermagem e dois pós-graduandos do Programa de Pós-Graduação Enfermagem em Saúde Pública da Escola de Enfermagem de Ribeirão Preto da Universidade de São Paulo (EERP-USP), com grupos de puérperas, gestantes e suas famílias, em dois hospitais de Ribeirão Preto-SP, o Centro Estadual de Referência à Saúde da Mulher (Mater) e o Hospital das Clínicas da Faculdade de Medicina de Ribeirão Preto da Universidade de São Paulo (HCFMRP-USP).

Estas atividades educativas estão vinculadas ao projeto de extensão universitária $O$ cuidado ao bebê prematuro: utilização de metodologias ativas e objeto de aprendizagem na educação em saúde da família na unidade neonatal. A proposta da extensão consiste em oferecer às famílias de bebês prematuros uma forma de orientação mais inclusiva do ponto de vista da participação dos pais e familiares, com características didáticas baseadas no lúdico, no uso de materiais de ensino, como jogos educativos e na cartilha Guidados com o bebê prematuro: orientações para a família, de Fonseca e Scochi [4], que utiliza figuras coloridas, linguagem adequada, fácil entendimento e que a família pode levar para consulta em casa. Além do estímulo à participação, o projeto tem o intuito de auxiliar as famílias no processo de empoderamento e autonomia do cuidado de seu bebê.

Foram realizadas ações de educação em saúde lúdico-pedagógicas semanais junto aos familiares de bebês prematuros e de risco assistidos no HCFMRP-USP, tanto no alojamento conjunto neonatal como nas unidades de cuidados intensivos e intermediários neonatais. $\mathrm{Na}$ Mater, os encontros ocorreram na sala de cursos do ambulatório, com as puérperas que aguardavam a alta hospitalar após avaliações clínicas do binômio pela equipe de saúde, e com gestantes, mães e familiares que se faziam presentes na unidade para acompanhamento prénatal. Inicialmente, o projeto foi pensado apenas para a família do bebê pré-termo. Porém, por solicitação da equipe de saúde dos hospitais e da própria clientela, e entendendo que as discussões não englobam apenas as especificidades do nascimento prematuro, mas que as famílias expressavam suas dúvidas, muitas vezes sobre os cuidados simples do cotidiano, as atividades foram expandidas para as famílias dos bebês a termo.
É importante relatar que houve diminuta participação de familiares como pai, avó e avô e tios nos encontros de ambos os cenários de desenvolvimento do projeto de extensão. A presença das mães foi mais expressiva devido à relação mais próxima entre mãe e bebê nos processos conjuntos de cuidar e amamentar e pelo papel comumente assumido pela mulher em relação ao seu filho. Muitos familiares expressaram o desejo de participação nas atividades educacionais propostas, mas estavam trabalhando nestes períodos.

A mulher é considerada a principal responsável pelo cuidado da família, sendo ela, na maioria das vezes, a cuidadora cotidiana dos filhos. A criança, após o nascimento, é totalmente dependente; embora possua todas as potencialidades para sobreviver, precisa de cuidados que não pode prestar a si mesma, sendo geralmente a mãe a cuidadora, segundo Zanatta e Motta [I3] .

Optamos por não realizar as atividades educativas em horário próximo ao de visita devido à ansiedade das mulheres que aguardavam seus familiares e consequente comprometimento na participação nas atividades.

Com o objetivo de aperfeiçoar a estratégia de intervenção, foram realizados previamente, e durante as atividades, estudos teóricos sobre a temática educação em saúde, autonomia dos usuários dos serviços de saúde, metodologias ativas e desenvolvimento e uso de materiais educacionais.

Os materiais de ensino utilizados variaram a cada encontro, sendo mais utilizados os jogos de tabuleiro, jogo de cartas, cartilha, figuras de situações do cotidiano para discussão e folders. No início das reuniões era sempre realizada a apresentação dos participantes, com dinâmicas e, ao final das atividades, eram distribuídos exemplares da cartilha educativa.

O uso e posterior distribuição da cartilha educativa são justificados pela necessidade, relatada pelas famílias no contato em serviços de saúde, de ter um material em mãos que pudessem ler mais calmamente e quando a dúvida surgisse em casa.

Acreditamos que as dinâmicas ativas, auxiliadas pelo uso dos materiais de ensino acima citados, favoreceram a interação entre as participantes que foram pró-ativas nas discussões, uma vez que as atividades permearam a troca de experiências e manifestação de dúvidas, crenças e preocupações. Os jogos de tabuleiro foram desenvolvidos por Fonseca e Scochi [2] e se intitulam Mamãe e o bebê e Mamãe e o pequeno bebê, voltados para recém-nascidos a termo e pré-termo, respectivamente. 
Para a sua execução, os participantes eram divididos em grupos, identificados com crachás coloridos preparados manualmente, e eram explicadas as regras da atividade, destacando que não se tratava de uma aula tradicional e que a participação de todos era muito importante, de modo que qualquer dúvida ou opinião deveria ser manifestada para uma maior troca de experiências.

O jogo de cartas foi criado pelas estudantes de graduação especificamente para as atividades de educação em saúde, contendo figuras que eram distribuídas para fomentar as discussões da roda, como disparador. As figuras foram extraídas da própria cartilha, de modo que a mãe, ao ler a cartilha posteriormente, pudesse associar a figura já manuseada com o conhecimento construído no grupo.

Além disso, foram distribuídos folders de orientação sobre o cuidado do bebê, sua saúde e hospitalização nas atividades no HCFMRP. O público, em roda, era estimulado à discussão e ao esclarecimento de questões relevantes à saúde da criança.

As atividades educativas embasadas nas metodologias ativas permitiram a participação ativa dos envolvidos, contribuindo muito com as discussões e construção dos seus próprios conhecimentos. De diferentes formas, cada participante cooperou com as discussões, afirmando temas com base em crenças e informações anteriormente obtidas, relatando experiências prévias, suas dúvidas, que desconhecia informações ou que nunca havia refletido sobre o assunto antes.

As metodologias ativas estão alicerçadas em um princípio teórico significativo: a autonomia, segundo Freire [7]. A busca da autonomia pode ser potencializada pela interação com o outro.

A interação entre os envolvidos foi estimulada não somente pelos estudantes, mas também pelos próprios participantes, de modo que a troca de experiências e as respostas às dúvidas saíram dos seus pares; os estudantes interferiram apenas nas colocações que representariam riscos à saúde das crianças.

As principais demandas de discussão permearam conteúdos referentes aos cuidados do cotidiano: banho e higiene do recém-nascido; segurança; ordenha mamária; amamentação e outros alimentos; cólica e choro do bebê; sinais de risco; uso de mamadeiras e chupetas; banho de sol e outros temas.

No estudo de Fonseca et alli [3], os participantes das atividades educativas trouxeram, através de círculos de discussão, os assuntos de interesse para o processo ensino-aprendizagem sobre seus bebês, agrupados em: cuidados diários; alimentação; higiene; cuidados especiais e relacionamento familiar. Estes assuntos são voltados para as práticas cotidianas, de cuidados simplificados.

As crenças e os costumes, há muito desmistificados, ainda foram manifestados pelos participantes, demonstrando que as informações consideradas adequadas, muitas vezes, se restringem a determinada população, ou que as opiniões que constituem o senso comum acerca da saúde do binômio mãe-bebê ainda são muito fortes, mesmo na era da comunicação e informação.

Por outro lado, destacamos as manifestações de participantes que se basearam em informações adquiridas em sites on-line de saúde do bebê voltados para apoio de pais. Isto demonstra autonomia e interesse relativo à busca de conhecimentos em saúde, além da utilização de meios tecnológicos para o aprendizado desta natureza. Muitos também relataram informações adquiridas por meio de programas de televisão e telejornais. Orientamos aos participantes que, quando navegassem pela internet à procura de informações sobre saúde, dessem preferência aos sites governamentais e artigos científicos.

A partir disso, podemos refletir que a atitude dos pais em procurar respostas aos seus questionamentos auxilia no empoderamento da família no cuidado ao seu bebê e na tomada de decisão para preservar sua saúde e prevenir agravos. Contraditoriamente, a família está mais exposta às informações inadequadas disponíveis na internet; demonstrando a importância do papel educativo do profissional de saúde.

O período pós-parto é carregado de mitos, crenças e costumes que necessitam de atenção do profissional, que deve respeitar as crenças e as práticas culturais de cada família, na medida em que não prejudiquem a saúde do filho. O cuidado, permeado por práticas culturais, vem através das gerações; a equipe, muitas vezes, não as valoriza, e até despreza essas crenças, gerando conflitos com as famílias, segundo Tomeleri e Marcon [12].

Cabe ressaltar que os envolvidos nas atividades de educação em saúde expressaram que se sentiram satisfeitos e felizes por poder tirar dúvidas sem medo e constrangimento, por colaborar com o grupo através de experiências próprias e que ainda se divertiram em aprender jogando, esquecendo que estavam no hospital.

Além da efetiva participação das famílias, em 
alguns encontros realizados na Mater contamos com a presença de diferentes profissionais da área da saúde, como nutricionista, enfermeira, psicóloga e assistente social. Não foi possível a manutenção fixa deste grupo multiprofissional em todos os encontros devido às várias demandas de atendimentos realizados por ele. Todavia, ressaltamos a riqueza das discussões quando incorporados tais profissionais ao grupo. Esta possibilidade de participação já foi sugerida em estudo anterior por Delfino et alli [I], bem como foi sugerida elaboração de mais estudos, com metodologia participante e colaboração interdisciplinar em saúde, para fins de produção de novos conhecimentos com atenção às múltiplas dimensões e conexões manifestadas mediante este tipo de integração.

Pela alta precoce, para a maioria das famílias participantes das atividades, foi realizado apenas um encontro de cerca de uma hora. Isto gerou ansiedade nas estudantes por terem pouco tempo para a discussão de tantos assuntos. As estudantes entenderam que os assuntos levantados durantes as discussões eram as principais dúvidas e que este momento de encontro estimulou as famílias a repensar outros. Reconhecemos a importância da alta precoce e a continuidade da assistência na atenção primária à saúde, acreditando que seria uma estratégia interessante a implantação de grupos de educação e apoio no continuum da assistência. Em 2000, Frederico, Fonseca e Nicodemo [5] sugeriram a articulação entre o serviço de atendimento domiciliar e o hospitalar onde foi realizada intervenção educacional, através da qual seria possível verificar a aplicabilidade dos conhecimentos apreendidos e auxiliar as famílias em outras dúvidas e necessidades de saúde.

Cabe salientar que, eventualmente, algumas gestantes que acompanham o pré-natal na Mater compareceram mais de uma vez nos encontros. Elas puderam contribuir com o grupo com base em conhecimentos construídos anteriormente, sentindo-se mais confiantes com a informação e satisfeitas por poder colaborar com outras famílias; estas relataram a importância destes momentos de troca de informações e experiências.

Examinando atentamente as atividades educacionais em grupo, é importante considerar a possibilidade de conflitos e choque de opiniões entre os participantes e a necessidade de preparo do facilitador frente a tais situações. O tema saúde contém assuntos permeados por saberes científicos e de senso comum, sendo que este último ainda apresenta variações que dependem da cultura familiar e das experiências de vida, o que pode gerar pluralidade de pontos de vista a respeito de um mesmo aspecto e, mesmo que implicitamente, conflitos.

Este fato foi relatado por Mafficioli e Lopes [9] em sua intervenção; também destacamos raras ocorrências de tal situação em nossas atividades. É fundamental que o assunto seja retomado e os demais participantes sejam encorajados a contribuir com novas informações e experiências, no intuito de socializar a questão, com o cuidado de evitar o subjugo de qualquer pessoa envolvida na interação grupal.

\section{CONSIDERAÇÕES FINAIS}

Ponderando a respeito da relevância do papel de educador do enfermeiro no serviço de saúde, acreditamos que a iniciativa do projeto tem estimulado os profissionais de saúde dos dois hospitais na ampliação das atividades e a investirem na eficácia e na qualidade das orientações oferecidas no cotidiano.

Acreditamos que as metodologias ativas de aprendizagem dinamizam as atividades e potencializam as discussões e a construção pró-ativa dos conhecimentos. As atividades educativas tornaram-se mais atrativas e inclusivas por valorizar o conhecimento do outro e considerar suas experiências prévias. Estas características estimularam a atenção e a motivação para aprender e ensinar não somente por parte da clientela, mas também dos profissionais, que se sentiram instigados a ousar nas inovações educacionais e dar voz à clientela.

As atividades de educação em saúde realizadas neste projeto de extensão universitária contribuíram com o processo de construção e integração do saber de familiares e equipe de saúde neonatal. Contribuíram para a construção de uma assistência mais integral e humanizada, bem como auxiliaram na busca da autonomia e emancipação das famílias dos bebês, inclusive de risco, no tocante aos cuidados com seus filhos e promoção de saúde.

Os encontros de educação em saúde contribuíram com a formação dos estudantes a partir da inserção em projeto de extensão de serviços à comunidade e em reuniões técnico-científicas, instigando-os a pensar novas formas de assistir participativamente. 


\section{REFERÊNCIAS BIBLIOGRÁFICAS}

[I] DELFINO, M. R. R. et al. O processo de cuidar participante com um grupo de gestantes: repercussões na saúde integral individual-coletiva. Giência \& Saúde Coletiva, v. 9, n. 4, p. I057-I066, 2004.

[2] FONSEGA, L. M. M.; SCOCHI, G. G. S. Inovando a assistência de enfermagem ao binômio mãe-filho em alojamento conjunto neonatal através da criação de um jogo educativo. Revista Latino-Americana de Enfermagem, v. 8, n. 5, p. I06-I08, 2000.

[3] FONSEGA, L. M. M. et al. Cartilha educativa para orientação materna sobre os cuidados com o bebê prematuro. Revista Latino-Americana de Enfermagem, v. I2, n. I, p. 65-75, 2004.

[4] FONSEGA, L. M. M.; SGOCHI, G. G. S. Cuidados com o bebê prematuro: orientações para a família. Ribeirão Preto: FIERP, 2009. 64 p.

[5] FREDERICO, P.; FONSECA, L. M. M.; NICODEMO, A. M. C. Atividade educativa no alojamento conjunto: relato de experiência. Revista Latino-Americana de Enfermagem, v. 8, n. 4, p. 38-44, 2000.

[6] FREIRE, P. Pedagogia do oprimido. 45. ed. Rio de Janeiro: Paz e Terra, 2006a.

[7] FREIRE, P. Pedagogia da autonomia: saberes necessários à prática educativa. 33. ed. São Paulo: Paz e Terra; $2006 \mathrm{~b}$.

[8] MACHADO, M. F. A. S. et al. Integralidade, formação de saúde, educação em saúde e as propostas do SUS - uma revisão conceitual. Giência \& Saúde Coletiva, v. I2, n. 2, p. 335-342, 2007.

[9] MAFFAGGIOLLI, R.; LOPES, M. J. M. Educação em saúde: a orientação alimentar através de atividades em grupo. Acta Paulista de Enfermagem, v. I8, n. 4, p. 439-445, 2005.

[IO] PEREIRA, A. L. Educação em saúde. In: FIGUEIREDO, N. M. A. (org.). Práticas de enfermagem: ensinando a cuidar em saúde pública. São Paulo: Difusão, 2003.p. 25-46.

[iI] TOlEDO, M. M.; RODRIGUES, S. G.; GHIESA, A. M. Educação em saúde no enfrentamento da hipertensão arterial: uma nova ótica para um velho problema. Texto \& Contexto Enfermagem, v. I6, n. 2, p. 233-238, 2007.

[i2] TOMELERI, K. R.; MARGON, S. S. Práticas populares de mães adolescentes no cuidado aos filhos. Acta Paulista de Enfermagem, v. 22, n. 3, p. 272280, 2009 . [i3] ZANATTA, E. A.; MOTTA, M. G. C. Saberes e práticas de mães no cuidado à criança de zero a seis meses. Revista Gaúcha de Enfermagem, v. 28, n. 4, p. $556-563,2007$. 